\title{
Flat-Rate Design Method for Low- and Medium-Rise Reinforced Concrete Structures
}

\author{
by Adolfo Matamoros, Luis E. García, JoAnn Browning, and Andres Lepage
}

A simplified procedure to proportion earthquake-resistant reinforced concrete structures without irregularities is presented. The flatrate method may also be used to assess the vulnerability of existing structures to earthquakes in a simple manner. The method is based on the concept that the maximum expected roof drift of a building is proportional to the ratio of total mass to stiffness of the lateral load resisting system. This method is not intended to provide sharp details about the expected performance of buildings but to evaluate the overall earthquake resistance of building configurations in a simple manner. For this reason, it is intended for the evaluation or design of low- and medium-rise reinforced concrete structures. A number of design examples were completed with various performance objectives and included buildings with two and five stories and lateral load resisting systems with moment resisting frames and structural walls. For the performance objectives defined in the study, the use of structural walls was more cost-effective than moment resisting frames.

Keywords: design strength; reinforced concrete; seismic.

\section{INTRODUCTION}

The emergence of building performance as a viable criterion for gaging the earthquake vulnerability of new and existing structures has increased the use of more complex analysis methods, such as dynamic or static nonlinear analysis, to obtain consistent and reasonable estimates of strains, deflections, rotations, and other parameters used as indicators of tolerable levels of damage in structural elements and systems. These types of analyses are subject to intricate modeling decisions and may present engineers a large work burden, which may not be justifiable for preliminary or simple design situations or in regions of moderate seismic risk. Simplified techniques are a useful resource because they require few calculations and can be calibrated to yield reasonable estimates of expected level of performance. These estimates also may be used to complement more complex methods of analysis.

\section{RESEARCH SIGNIFICANCE}

The flat-rate design method is a simplified procedure for proportioning earthquake-resistant reinforced concrete structures to achieve a given performance objective. The basis for the method is the adoption of the maximum storydrift ratio (SDR) - defined as the ratio of maximum story drift to total story height-as the main indicator of the expected level of damage in a structure. The study shows that by using very simple expressions, the expected performance for a regular low-rise building structure can be improved with an increase in the ratio of lateral stiffness to the mass of a structure.

\section{BACKGROUND}

The underlying philosophy of the flat-rate method is to limit damage by controlling the drift response of a structure. Drift is defined as the displacement response of the structure measured from a vertical line projected from the base. The philosophy is implemented by requiring a minimum structural stiffness (represented by the cross- sectional areas of the vertical elements in the structure) to mass (represented by the total floor area of the structure) ratio and then verifying the adequacy of this criterion with a simple estimate of drift. Longitudinal steel is selected for the elements by considering only gravity loads, and detailing is provided to allow the requisite amount of drift to occur without brittle failure to any element. The base shear strength of the structure is then compared with a threshold strength requirement, but this is generally satisfied without increasing the element strengths. In this way, the method represents a departure from traditional design methods by first satisfying a stiffness criterion and then verifying that the strength of the structure is adequate. Throughout the paper, the term design is used to convey the process of selecting the dimensions and detailing for the structure. The method eliminates cumbersome calculations with multiple lateral load combinations and it emphasizes the dependency of damage on the drift response of the structure.

An estimate of drift can be derived by considering the elastic acceleration and displacement response spectra shown in Fig. 1. The acceleration response spectrum in Fig. 1(a) was defined using the provisions provided by NEHRP (FEMA 368 2001) as implemented in SEI/ASCE 7-02 (2003) and adopted in IBC-2003 (2003) and NFPA 5000 (2003). The solid black line shown in Fig. 1(b) represents the equivalent displacement response spectrum for the acceleration response spectrum. The gray line in Fig. 1(b) represents a similar displacement response spectrum with increased damping.

The estimate of drift can be obtained using the substitute structure method (Shibata and Sozen 1976), as implemented by Shimazaki and Sozen (1984). Shimazaki and Sozen found that the elastic drift obtained from a spectrum with low damping and using an effective initial fundamental period $T_{\text {eff }}$ provided a good estimate of the maximum amount of drift during the nonlinear response for that system, which would result in an increased period and increased damping (Fig. 1(b)). The effective initial period was defined as

ACI Structural Journal, V. 101, No. 4, July-August 2004

MS No. 02-290 received August 1, 2002, and reviewed under Institute publication policies. Copyright (C) 2004, American Concrete Institute. All rights reserved, including the making of copies unless permission is obtained from the copyright proprietors. Pertinent discussion including author's closure, if any, will be published in the May-June 2005 ACI Structural Journal if the discussion is received by January 1, 2005 
ACI member Adolfo Matamoros is an assistant professor in the Department of Civil Engineering at the University of Kansas, Lawrence, Kans. He received his doctoral degree from the University of Illinois at Urbana-Champaign, Urbana, Ill. He is a member of ACI Committees 341, Earthquake-Resistant Concrete Bridges; 408, Bond and Development of Reinforcement; 439, Steel Reinforcement; and Joint ACI-ASCE Committee 445, Shear and Torsion.

Luis E. García, FACI, is Senior Partner and President of Proyectos y Diseños Ltda., a consulting structural design firm in Bogotá, Colombia. He teaches at the Universidad de los Andes, Bogotá. He received his BSc in civil engineering from the Universidad de los Andes and his MSc from the University of Illinois at Urbana-Champaign. He is a member of ACI Committees 318, Structural Concrete Building Code; 374, PerformanceBased Seismic Design of Concrete Buildings; 439, Steel Reinforcement; Joint ACIASCE Committee 352, Joints and Connections in Monolithic Concrete Structures; the Fellows Committee; the International Committee; and the International Conferences/ Conventions Committee.

ACI member JoAnn Browning is an assistant professor at the University of Kansas. She received her PhD from Purdue University, West Lafayette, Ind. She is a member of ACI Committees 318-D, Flexure and Axial Loads; 341, Earthquake-Resistant Concrete Bridges; 374, Performance-Based Seismic Design of Concrete Buildings; and 408, Bond and Development of Reinforcement. Her research interests include analysis and design of earthquake-resistant concrete structures.

ACI member Andres Lepage is an associate with KPFF Consulting Engineers, Seattle Wash. He received his $\mathrm{PhD}$ from the University of Illinois at Urbana-Champaign. He is a member of ACI Committees 335, Composite and Hybrid Structures; 369, Seismic Repair and Rehabilitation; 374, Performance-Based Seismic Design of Concrete Buildings; 375, Performance-Based Design of Concrete Buildings for Wind Loads; and Joint ACI-ASCE Committee 445, Shear and Torsion.

$$
T_{\text {eff }}=\sqrt{2} T_{i}
$$

where $T_{i}$ is the initial period of the structure calculated using gross section properties. This procedure was found to work well for structures with $T_{i}$ greater than the corner period $T_{S}$, which marks the transition between the nearly constant acceleration response and the nearly constant velocity response in the response spectrum of single degree of freedom systems. For the remaining systems, strength was an important parameter for estimating drift. Lepage (1997) provided a convenient solution for short-period structures by simply extending the spectrum for the nearly constantvelocity region as a line through the origin (Fig. 1(b)). By using the Lepage spectrum, the response of short-period structures was also captured using the Shimazaki and Sozen method.

The spectral displacement $S_{d}$ for reinforced concrete structures as simplified by Lepage (1997) can be written

$$
S_{d}=\frac{C_{\alpha} \cdot \alpha \cdot g \cdot T_{S}}{(2 \pi)^{2}} \cdot T_{e f f}
$$

where $C_{\alpha}$ is the acceleration amplification factor, $\alpha$ is the effective peak ground acceleration as a fraction of the acceleration of gravity, $g$ is the acceleration of gravity, $T_{S}$ is the corner or characteristic period for a given spectrum, and $T_{\text {eff }}$ is the effective initial period as defined using Eq. (1) with $T_{i}$ calculated using uncracked-section properties. A drift response estimate may be obtained by replacing the product of the coefficients $C_{\alpha} \cdot \alpha$ with the coefficient $S_{D S}$, from the seismic data published by USGS (Frankel et al. 2000). The level of confidence of the drift estimate may be adjusted based on the acceleration amplification factors $C_{\alpha}$ provided by Newmark and Hall (1982) for various levels of damping (Matamoros, Browning, and Luft 2003). Similarly, the value of $T_{S}$ may be calculated as $S_{D 1} / S_{D S}$. Substituting accordingly in Eq. (2), the spectral displacement is approximated by

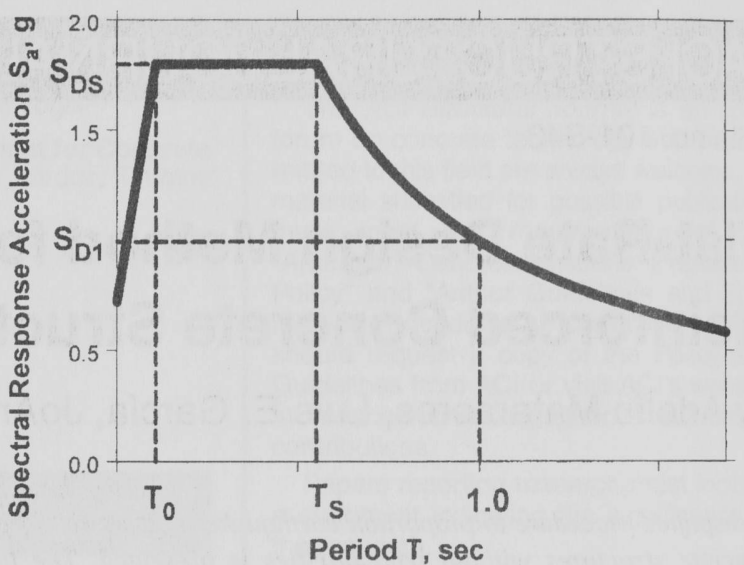

(a)

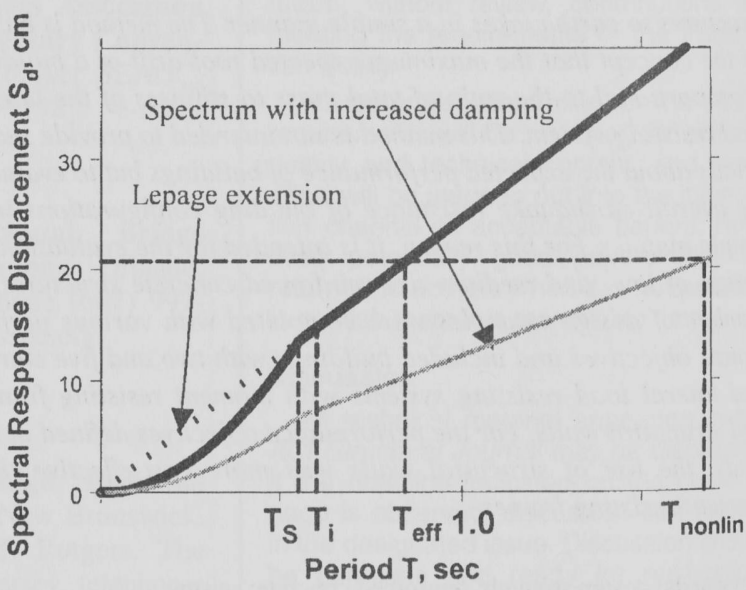

(b)

Fig. 1-(a) Acceleration spectrum; and (b) displacement response spectrum.

$$
S_{d}=\frac{1}{40} S_{D S} \cdot T_{S} \cdot T_{e f f} \cdot g
$$

For a multistory building, the spectral displacement $S_{d}$ is related to the roof displacement

$$
D_{\text {roof }}=\gamma \cdot S_{d}
$$

where $\gamma$ is the modal participation factor for a shape vector normalized to unity at the roof and is representative of the predominant deflected shape of the building. A $\gamma$ factor of 1.3 is assumed as a representative value for the fundamental mode of low-rise regular structures. If the mean-drift ratio (MDR) is defined as the total lateral roof drift divided by the total structure height $h_{\text {roof }}$, then an estimate of MDR $\left(M D R_{\text {est }}\right)$ may be obtained using

$$
M D R_{\text {est }}=\frac{1}{30} \frac{S_{D S} \cdot T_{S} \cdot g}{h_{\text {roof }}} \cdot T_{\text {eff }}
$$

The maximum SDR (maximum ratio of story drift to story height) is often preferred to mean drift ratio as a measure of performance in model codes. An estimate of SDR can be found based on the observation that, barring story mechanisms, the deformed shape of the structure during nonlinear response is similar to that of the linear range of response 
(Otani and Sozen 1972; Sozen 1981; Moehle 1984). Knowing this, SDR is related to the maximum MDR as

$$
S D R_{\text {est }} \cong 1.3 M D R_{\text {est }}=\frac{4}{90} \cdot \frac{S_{D S} \cdot T_{S} \cdot g}{h_{\text {roof }}} \cdot T_{\text {eff }}
$$

Equation (6) is used as part of the flat-rate method to determine whether the proportioned structure will experience a tolerable amount of drift given the seismic demand at the site. This equation is not intended to provide a precise estimate of SDR but an approximate number based on the assumptions introduced into its derivation.

The procedure for estimating SDR as described previously has been shown to provide a reasonable estimate of drift for structures having a requisite amount of base shear strength (Shimazaki and Sozen 1984; Lepage 1997; Browning 2001). To satisfy minimum strength requirements, the base shear strength of the structure $V_{b}$ must satisfy the minimum criterion defined by Eq. (7) (Lepage 1997)

$$
V_{b} \geq V_{r}
$$

with

$$
V_{r}=\frac{S_{D S}}{2.5} \cdot\left(1-\frac{T_{e f f}}{T_{S}}\right) \cdot W \geq \frac{S_{D S} \cdot W}{15}
$$

where $W$ is the weight of the building, and the value of the ratio $T_{\text {eff }} / T_{S}$ shall not be taken as greater than $5 / 6$. The term $S_{D S} / 2.5$ is meant to represent the effective peak ground acceleration.

Equation (6) was derived based on the assumption that the ratio of base shear strength of the building $V_{b}$ to the elastic seismic demand is small, typically below 0.2 (Lepage 1997). In the case of buildings with $T_{\text {eff }} / T_{S} \leq 1$, the combination of stiffness and minimum reinforcement requirements may result in much higher ratios of base shear strength to elastic seismic demand. In these cases, the mean drift ratio estimated with Eq. (5) can be overly conservative, and a correction factor for the mean drift ratio is given by

$$
C F_{M D R}=1-\frac{V_{b}}{W \cdot S_{D S}}\left(1-\frac{T_{e f f}}{T_{S}}\right) \leq 1.0
$$

The development of Eq. (9) is presented in detail in the Appendix.

\section{Implementation of flat-rate method}

As shown in Fig. 2, the flat-rate procedure consists of four basic steps.

Step 1: Define element dimensions-The objective of the - first step is to establish preliminary dimensions for building elements. To achieve the stated performance objective, element dimensions should be determined according to the following guidelines.

Column dimensions - In an economic study of reinforced concrete buildings with various configurations ranging from four to 20 stories in height, it was determined that the total cost of the building was best managed when the column sizes were selected before girder sizes (García 1996). Trends in equal-cost lines suggested that the total cost was significantly

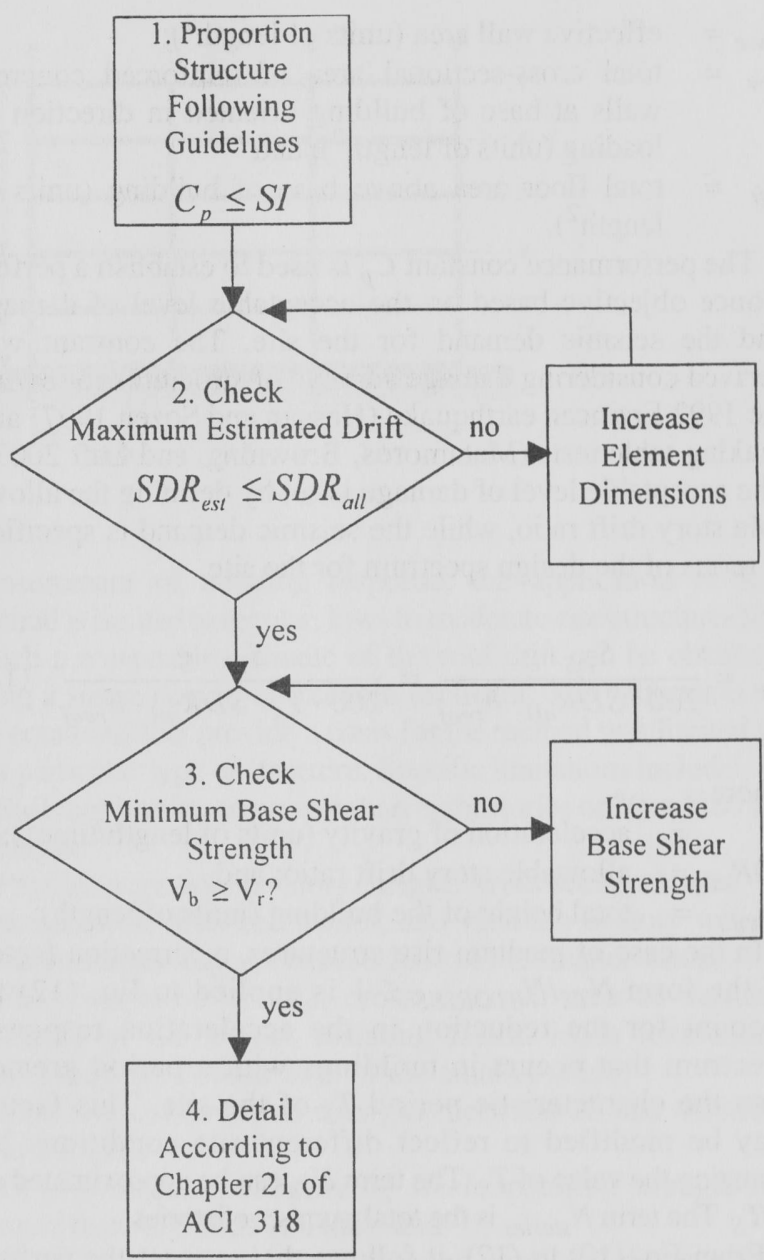

Fig. 2-Flate-rate proportioning method.

more sensitive to column dimensions than it was to girder dimensions. Consistent with this approach, preliminary column sizes are first established for the flat-rate method based on the performance criterion given by

$$
C_{p} \leq \mathrm{SI}
$$

The two indexes presented in Eq. (10) are the performance constant $C_{p}$ and the structural index SI. The structural index is adopted as a rough indicator of the ratio of lateral stiffness to mass of the structure. In this way, it can be related to the fundamental structural period and, thus, related to drift (as discussed previously). The SI was developed in a study of damage surveys of reinforced concrete structures following the 1992 Erzincan earthquake (Hasaan and Sozen 1997) and adjusted with a study of shaking table tests to better reflect the effects of wall height-to-width ratios, $H_{\text {wall }} / L_{\text {wall }}$ (Matamoros, Browning, and Luft 2003) on the measured drift response of buildings. SI is defined as

$$
\mathrm{SI}=\frac{100 \cdot\left(0.5 \cdot A_{c}+A_{w e}\right)}{A_{f t}}, A_{w e}=\frac{100 \cdot A_{w}}{30+\left(H_{\text {wall }} / L_{\text {wall }}\right)^{2}}
$$

where

$A_{c}=$ the total cross-sectional area of columns at base of building (do not consider columns supporting flatplate floor systems) (units of length ${ }^{2}$ ); 
$A_{w e}=$ effective wall area (units of length ${ }^{2}$ );

$A_{w}=$ total cross-sectional area of reinforced concrete walls at base of building oriented in direction of loading (units of length ${ }^{2}$ ); and

$A_{f t}=$ total floor area above base of building (units of length ${ }^{2}$ ).

The performance constant $C_{p}$ is used to establish a performance objective based on the acceptable level of damage and the seismic demand for the site. The constant was derived considering damage surveys of structures following the 1992 Erzincan earthquake (Hasaan and Sozen 1997) and shaking table tests (Matamoros, Browning, and Luft 2003). The acceptable level of damage is set by defining the allowable story drift ratio, while the seismic demand is specified in terms of the design spectrum for the site

$$
C_{p}=\frac{S_{D S} \cdot g}{200 \cdot S D R_{\text {all }} \cdot h_{\text {roof }}}=\frac{S_{D 1} \cdot g}{200 \cdot T_{S} \cdot S D R_{\text {all }} \cdot h_{\text {roof }}}
$$

where

$$
\begin{aligned}
& g=\text { acceleration of gravity (units of length/time }{ }^{2} \text { ); } \\
& S D R_{\text {all }}=\text { allowable story drift ratio; and } \\
& h_{\text {roof }}=\text { total height of the building (units of length). }
\end{aligned}
$$

In the case of medium-rise structures, a correction factor of the form $N_{T S} / N_{\text {STORIES }} \leq 1$ is applied to Eq. (12) to account for the reduction in the acceleration response spectrum that occurs in buildings with a period greater than the characteristic period $T_{S}$ of the site. This factor may be modified to reflect different site conditions by changing the value of $T_{S}$. The term $N_{T S}$ can be approximated as $10 T_{S}$. The term $N_{\text {stories }}$ is the total number of stories.

From Eq. (10) to (12), it follows that to meet the performance criterion, the minimum area of walls and columns in the building must be as indicated by Eq. (13).

$$
0.5 \cdot A_{c}+A_{w e} \geq \frac{S_{D S} \cdot g \cdot A_{f t}}{20,000 \cdot S D R_{\text {all }} \cdot h_{\text {roor }}}
$$

For some levels of demand or performance criteria, it may become necessary to use structural walls for an efficient design. In general, for performance levels that restrict the allowable story drift to less than $0.75 \%$ of the story height (García 1996), it becomes uneconomical to use moment resisting frames as the main lateral load resisting system, and it is recommended to use structural walls.

Girder dimensions - For performance objectives that are intended to guarantee life safety in areas of high and moderate seismicity, girder depths appropriate to resist gravity loads (typically between 8 and $10 \%$ of the length of the span) will provide a sound preliminary earthquakeresistant structure. As performance objectives become more stringent, either because the allowable drift limit is very low or the magnitude of the design ground motion is unusually high, column sizes dictated by Eq. (13) will increase considerably and the dimensions of the girders must be adjusted accordingly to maintain balanced proportions. Furthermore, in the economic evaluation of four- to 20 -story reinforced concrete buildings, it was shown that increasing the girder depth as the column dimensions are increased resulted in the most efficient structural configuration for controlling the total amount of story drift (García 1996). A constraining factor for selecting the size of the girders is that a strong column-weak beam mechanism is vital, which has the practical implication of setting an upper limit to the dimensions of the girders. After column sizes are determined based on Eq. (13), the following guideline is suggested for determining preliminary dimensions of the girders:

a. The depth of the girder $h_{g}$ should be no smaller than $85 \%$ of the dimension of the column that the girder is framing into (determined based on Eq. (13)).

b. The width of the girders should be approximately $1 / 2$ the depth.

Additional requirements - Column and girder sizes determined according to the "Column dimensions" and "Girder dimension" sections should result in a preliminary design that will approximately meet the specified performance objective. The following requirements are given as suggested limits for the use of the method:

a. For girders, $4 \leq L / h_{g} \leq 16$, and $h_{g} \geq 250 \mathrm{~mm}$ (10 in.), where $L$ is the span length (between column centers) and $h_{g}$ is the total girder depth. The girder width shall not be less than $0.3 h_{g}$;

b. For columns, $H / h \leq 8$, and $h$ and $t \geq 300 \mathrm{~mm}$ (12 in.), $h / t \leq 2.5$, where $H$ is the total column height (between girder centers), and $h$ and $t$ are the largest and smallest dimensions of the column cross section, respectively; and

c. For structural walls, $H_{\text {wall }} L_{\text {wall }} \leq 8, L_{\text {wall }} / t_{\text {wall }}>2.5$, and $t_{\text {wall }} \geq 200 \mathrm{~mm}$ ( $8 \mathrm{in}$.), where $H_{\text {wall }}$ is the total height of the wall, $L_{\text {wall }}$ is the wall length, and $t_{\text {wall }}$ is the wall thickness. The requirement that $H_{\text {wall }} / L_{\text {wall }} \leq 8$ is best satisfied by using an entire bay to dimension all wall elements.

The main strength of the procedure described in Step 1 is that it provides a conservative estimate of building performance in a very simple manner. As a consequence of its simplicity, the procedure is not sensitive to several parameters that have an effect on the calculated period, including the flexibility of the girders, span length, and differences in column stiffness between frames oriented in orthogonal directions. To address these concerns and achieve a final structural configuration that conforms to the established performance criteria, initial proportions developed in Step 1 should be verified for proper resistance and stiffness to lateral loads. This objective is accomplished in Steps 2 and 3.

Step 2: Check drift limitations-An estimate of the expected maximum drift for the proportioned structure can be obtained using Eq. (6) as described previously. It is important to emphasize that this estimate is based on a calculated fundamental period for the structure (using uncracked sections) multiplied by $\sqrt{ } 2$. The estimated story drift ratio $S D R_{\text {est }}$ is then compared with a specified allowable value $S D R_{\text {all }}$

$$
S D R_{\text {est }} \leq S D R_{\text {all }}
$$

The value of $S D R_{\text {all }}$ is selected to satisfy a predetermined performance objective for the structure. Element dimensions should be increased if Eq. (14) is not satisfied.

Step 3: Check base shear strength-The base shear strength of the structure may be evaluated using limit analysis, as shown in the example buildings presented in this paper, or by using static nonlinear analysis. The strengths of the individual elements are determined by selecting longitudinal reinforcement for the columns, girders, and walls based on the gravity loading and prescribed building code minima, as explained in Step 4. Element dimensions obtained with proportioning guidelines from the "Column dimensions,", "Girder dimensions," and "Additional requirements" 

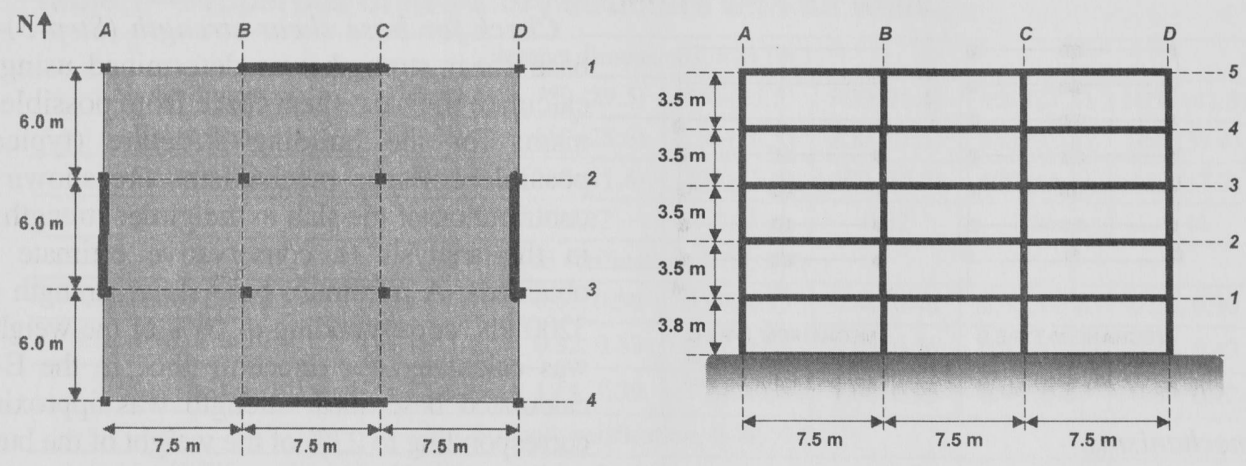

Fig. 3-Typical floor and elevation.

sections from Step 1 and conforming to Eq. (10) must be increased if required to provide adequate resistance to gravity and wind demands, although wind demands typically are not the controlling design quantity for buildings considered eligible for the flat-rate procedure (not greater than eight stories). To satisfy minimum strength requirements, the base shear strength of the structure $V_{b}$ must satisfy the minimum criterion defined by Eq. (7) and (8). The value of $M D R_{\text {est }}$ and $S D R_{\text {est }}$ should be adjusted using Eq. (9) if $T_{\text {eff }} / T_{S} \leq 1$.

Step 4: Detailing requirements for toughness-Detailing should be provided for all elements in the proportioned frame to satisfy the criteria for the seismic design category in the appropriate building code and the requirements of Chapter 21 of the ACI 318-02 Building Code (ACI Committee 318 2002). In addition, the required shear strength of the elements should be computed using the final probable moment strength calculated in Step 3. Walls should terminate in columns to provide proper boundary elements, and in such cases the confinement in the columns should be provided over the full length of the column height. Alternatively, the displacement demand on the walls may be calculated using Eq. (5) and used to evaluate the need for special boundary elements according to Eq. (21-8) of the ACI 318-02 Building Code (ACI Committee 318 2002).

It is essential that all members be detailed to sustain the nonlinear deformations that will take place in the structure to reach $S D R_{\text {all }}$ without the occurrence of brittle failures. In the study by Browning (2001) in which the dimensions of the elements were selected to satisfy a performance criterion of $1.5 \% M D R_{\text {all }}$ and the minimum reinforcement requirements established in Chapters 1 to 20 of the ACI 318-02 Building Code (ACI Committee 318 2002) were followed, it was observed that ductility demands on the elements were tolerable. This was because for a $1.5 \%$ MDR, the resulting maximum story drift ratio did not exceed $2 \%$, so that the element deformations were within reasonable performance limits. For similar performance criteria, the design provisions outlined in Chapter 21 of ACI 318 Building Code (ACI Committee 318 2002) should be suitable to obtain member deformation capacities required to achieve a range of performance objectives.

\section{LIMITATIONS OF FLAT-RATE METHOD}

According to the flat-rate method, the designer must verify that the structure complies with a specific performance objective that is selected in agreement with the building owner or satisfy a story drift requirement from a relevant building code. Compliance is established based on equations that relate the dimensions of the structural elements, the estimated story drift ratio, and the expected seismic demand. Because the method was neither derived nor intended to be used as a precise measurement of building response, the application of the method is limited to regular, low- to moderate-rise structures for which a reasonable estimate of the roof drift can be obtained using a single-degree-of-freedom oscillator. The calibration of the equations that provide a basis for the method was limited to this particular type of structure. Specific limitations include:

Building height: no greater than eight stories or $30 \mathrm{~m}$ (100 ft) in height;

Profile: variation in story height, cross-sectional area of structural walls between stories, and variation in story weight between stories may not exceed $20 \%$ of the smaller value;

Plan: variation of total cross-sectional area of vertical elements of the frames resisting lateral loads (excluding walls) may not exceed $20 \%$ of the smaller value;

Concrete compressive strength: between 20 and $40 \mathrm{MPa}$ (3 and $6 \mathrm{ksi})$;

Yield strength of reinforcing steel: specified strength no greater than $420 \mathrm{MPa}(60 \mathrm{ksi})$; and

Type of ground motion: Ground motions representing moderate to long focal distances. The implication of using this method for near-source ground motions has been studied by Ozturk (2003).

\section{DESIGN OF FIVE-STORY EXAMPLE BUILDING Description of building}

A five-story building was selected for a trial design to illustrate the use of the proposed method. Figure 3 shows the typical floor layout and the elevation of the building. Girders frame between each column in both directions of the building plan. All frames in both directions were considered part of the lateral-force-resisting system. Different performance objectives were investigated, each case proportioning the structure without structural walls and with two structural walls. Wall locations, when present, are shown in Fig. 3.

\section{Design loads and material properties}

Gravity loads used in all of the examples included a roof dead load of $5.9 \mathrm{kPa}\left(123 \mathrm{lb} / \mathrm{ft}^{2}\right)$, roof live load of $1.0 \mathrm{kPa}$ $\left(21 \mathrm{lb} / \mathrm{ft}^{2}\right)$, a typical floor dead load of $6.9 \mathrm{kPa}\left(144 \mathrm{lb} / \mathrm{ft}^{2}\right)$, and a typical floor live load of $2.5 \mathrm{kPa}\left(52 \mathrm{lb} / \mathrm{ft}^{2}\right)$. Reinforcing steel with $f_{y}=420 \mathrm{MPa}(60 \mathrm{ksi})$ was used both for longitudinal and transverse reinforcement, with 9.5 to $25 \mathrm{~mm}$ (3/8 to $1 \mathrm{in}$.) to bar diameters. Concrete strength $f_{c}{ }^{\prime}$ was $28 \mathrm{MPa}$ (4 ksi).

\section{Performance objective}

Calculations are presented for a performance objective with an allowable story drift ratio of $2.0 \%$ with $S_{D S}=1.25$. The proportioning was completed for a site with stiff soil conditions, where a characteristic period of $0.55 \mathrm{~s}$ is representative of the expected ground motion $\left(S_{D 1}=0.7\right)$. Element 


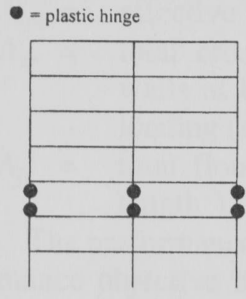
(Column hinges at top and bottom of any story)
MECHANISM TYPE A

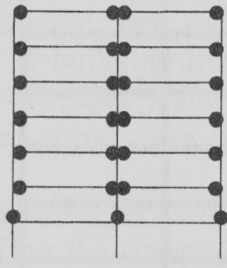

MECHANISM TYPE B (Column hinges at bottom of any story)

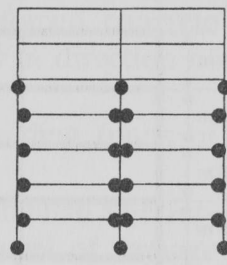

MECHANISM TYPE C (Column hinges at top of any story and at the base)
Fig. 4-Collapse mechanisms.

dimensions were calculated first for the structure with $S D R_{\text {all }}$ of $2.0 \%$ and without walls (2.0-nw), and appropriate adjustments were made for the structure with walls (2.0-ww).

\section{Proportioning of five-story structure without walls for $2 \%$ SDR ( $1.5 \%$ MDR) \\ Element dimensions (Step 1) - \\ Column dimensions: The performance constant $C_{p}$ is} computed using Eq. (12) to be 0.17 . By requiring that the structural index (SI) be at least equal to $C_{p}$, the total crosssectional area of columns at the base of the building is calculated using Eq. (13). The total column area at the base is $A_{c}$, and because no walls were employed in this case, $A_{w e}=0.0$. The total floor area above the base of the building $A_{f t}$ is $2025 \mathrm{~m}^{2}$, therefore, $A_{c}$ becomes $7.0 \mathrm{~m}^{2}$. Using the same dimensions for all columns, the area of one column is $\left(7.0 \mathrm{~m}^{2}\right) / 16=0.44 \mathrm{~m}^{2}$. Therefore, a $700 \mathrm{~mm}(28$ in.) square column section is appropriate.

Girder dimensions: Using the largest span $(7.5 \mathrm{~m})$, a girder depth is estimated to be $1 / 12$ of the span. A $600 \mathrm{~mm}$ deep girder is selected, which complies with the limit of $400 \mathrm{~mm}$ (16 in.). A $300 \mathrm{~mm}$ (12 in.) width corresponding to $1 / 2$ the depth is employed. All girders in both directions have the same dimensions.

Design for gravity and wind load: After the preliminary performance criteria were satisfied, structural element reinforcement to resist gravity and wind loads meeting the requirements for special moment frames in Chapter 21 of ACI 318-02 (ACI Committee 318 2002) was obtained.

\section{Drift check (Step 2) -}

Period computation: To verify the compliance with the drift limitations, a reasonable estimate of the fundamental period of vibration of the structure in the two principal directions in the plan is needed. This can be accomplished using a simple linear elastic computer model of the structure or by using the Rayleigh method. Uncracked section properties are used to define element stiffnesses, and the contribution of the slab to the stiffness of the girder sections was neglected (a conservative estimate for drift was obtained). The calculated value of the fundamental period obtained for each direction of the example structure using the Rayleigh method was $T_{E W}$ $=0.73 \mathrm{~s}$ and $T_{N S}=0.66 \mathrm{~s}$.

Drift verification: The effective initial period in each direction was calculated by multiplying the initial period values by $\sqrt{2}$ to obtain $T_{E W}$ and $T_{N S}$ of 1.03 and $0.93 \mathrm{~s}$, respectively. The story drift ratio was calculated using Eq. (6) (considering a roof height $h_{\text {roof }}$ of $17.8 \mathrm{~m}$ ) to be approximately 1.8 and $1.6 \%$ for the E-W and N-S directions, respectively. The estimated story drift ratios are within the allowable limit of $2.0 \%$ established by the performance criterion, and the element dimensions are deemed acceptable.
Check for base shear strength (Step 3)-The minimum base shear strength was determined using virtual work to calculate the base shear force from possible collapse mechanisms for the building structure (typical variations of possible collapse mechanisms are shown in Fig. 4). The contribution of the slab to the girder strength was not included in the analysis (a conservative estimate of strength was obtained). A minimum base shear strength of approximately $3200 \mathrm{kN}$, corresponding to $16 \%$ of the weight of the building, was calculated for direction N-S. In the E-W direction, the calculated base shear strength was approximately $4500 \mathrm{kN}$, corresponding to $23 \%$ of the weight of the building.

Values of 1.9 and 1.7 were obtained for ratio $T_{\text {eff }} / T_{S}$ in E-W and N-S directions, respectively. These ratios exceed the maximum value of $5 / 6$ permitted when evaluating the threshold base shear in Eq. (8). Therefore, the $5 / 6$ value was used to obtain

$$
\begin{gathered}
\left(V_{r}\right)=\frac{1.25}{2.50} \cdot(1-0.83) \cdot W \\
=0.085 \cdot W>\frac{0.5 \cdot W}{6}=0.085 \cdot W, \text { adequate }
\end{gathered}
$$

Therefore, the building has adequate base shear strength to satisfy the minimum requirement. Note that the longitudinal reinforcement in the example building was detailed for gravity loads based on element dimensions developed to limit the story drift ratio to $2.0 \%$. The resulting base shear strength in the weaker direction was $15 \%$ of the building weight. The ratio of base shear strength to the expected seismic demand may be used as an additional parameter by the designer to formulate the performance objective, noting that although an increase in strength will not have a significant effect on the overall drift, it should reduce the inelastic demands in the elements.

Seismic detailing (Step 4)-To meet the performance objective, requirements of Chapter 21 of ACI 318-02 (ACI Committee 318 2002) are adopted, including:

- For girders: longitudinal and transverse reinforcement as required in Sections 21.3.2 and 21.3.3. Shear reinforcement based on probable moment strength at the ends of the girder is provided;

- Verification of strong column weak beam as required by Section 21.4.2;

- For columns: longitudinal and transverse reinforcement as required in Sections 21.4.3 and 21.4.4. In addition, confinement is provided over the full length of the columns. Shear reinforcement based on probable moment strength at the ends of the column is provided; and

- For joints: longitudinal reinforcement, transverse reinforcement, and development of longitudinal reinforcement passing through the joint as required in Section 21.5.

\section{Proportioning of five-story structure with walls for $2 \%$ SDR (1.5\% MDR)}

\section{Element dimensions (Step 1) -}

Wall and column dimensions: The performance constant $C_{p}$ is the same as computed for the case without walls, which required a structural index of at least 0.17 . The proportioning process begins by selecting the minimum column size that is adequate to sustain the gravity load demands. In the case of the five-story structure analyzed in this example, a column depth of $400 \mathrm{~mm}$ was adopted. For this column size, $A_{c e}$ is 
Table 1-Properties of five-story structure without walls

\begin{tabular}{c|c|c|c|c|c|c|c}
\hline \multicolumn{7}{c}{ Element dimensions, mm (in.) } \\
\hline Column dimension & $650(25.6)$ & $750(29.5)$ & $850(33.5)$ & $900(35.4)$ & $950(37.4)$ & $1050(41.3)$ \\
\hline Beam depth & $550(21.7)$ & $650(25.6)$ & $750(29.5)$ & $800(31.5)$ & $850(33.5)$ & $950(37.4)$ \\
\hline Beam width & $250(9.8)$ & $300(11.8)$ & $350(13.8)$ & $400(15.7)$ & $400(15.7)$ & $450(17.7)$ \\
\hline SI & 0.17 & 0.22 & 0.29 & 0.32 & 0.36 & 0.44 \\
\hline \multicolumn{7}{c}{ Period verification, E-W, N-S } \\
\hline Calculated period $T, \mathrm{~s}$ & $0.83,0.79$ & $0.65,0.58$ & $0.50,0.45$ & $0.44,0.40$ & $0.41,0.36$ & $0.34,0.30$ \\
\hline Effective period $T_{\text {eff, }} \mathrm{s}$ & $1.18,1.12$ & $0.92,0.83$ & $0.71,0.64$ & $0.63,0.56$ & $0.57,0.51$ & $0.47,0.43$ \\
\hline$S D R_{\text {est }} \%$ (Eq. (6)) & $1.98,1.89$ & $1.54,1.39$ & $1.20,1.08$ & $1.06,0.95$ & $0.96,0.87$ & $0.80,0.72$ \\
\hline \multicolumn{7}{|c|}{ Strength verification, E-W, N-S } \\
\hline$V_{b} / W$ & $0.21,0.11$ & $0.23,0.17$ & $0.26,0.24$ & $0.29,0.29$ & $0.32,0.32$ & $0.40,0.41$ \\
\hline$V_{r} / W$ (Eq. (8)) & $0.08,0.08$ & $0.08,0.08$ & $0.08,0.08$ & $0.08,0.08$ & $0.08,0.08$ & $0.08,0.11$ \\
\hline \multicolumn{7}{|c|}{ Elastic drift for fundamental mode using 5\% damping response spectrum with $\alpha=0.5 g, \mathrm{E}-\mathrm{W}, \mathrm{N}-\mathrm{S}$} \\
\hline $\begin{array}{c}\text { Elastic MDR, \% } \\
\text { Maximum interstory } \\
\text { drift ratio, \% }\end{array}$ & $1.83,1.56$ & $1.26,1.12$ & $0.97,0.81$ & $0.78,0.63$ & $0.66,0.52$ & $0.45,0.36$ \\
\hline $\begin{array}{c}\text { Story with maximum } \\
\text { drift demand }\end{array}$ & $2.31,2.00$ & $1.63,1.47$ & $1.26,1.07$ & $1.02,0.83$ & $0.85,0.69$ & $0.59,0.47$ \\
\hline
\end{tabular}

Mass (weight) of reinforcing steel per unit area of building, $\mathrm{kg} / \mathrm{m}^{2}\left(\mathrm{lb} / \mathrm{ft}^{2}\right)$

\begin{tabular}{c|c|c|c|c|c|c}
\hline Column reinforcement & $10(2.1)$ & $14(2.9)$ & $19(4.0)$ & $21(4.4)$ & $23(4.8)$ & $29(6.1)$ \\
\hline Beam reinforcement & $11(2.3)$ & $12(2.5)$ & $14(2.9)$ & $17(3.6)$ & $17(3.6)$ & $23(4.8)$ \\
\hline Total reinforcement & $21(4.4)$ & $26(5.4)$ & $33(6.9)$ & $38(7.9)$ & $40(8.4)$ & $52(11)$ \\
\hline \multicolumn{7}{c}{ Volume of concrete (beams and columns), $\mathrm{m}^{3}\left(\mathrm{yd}^{3}\right)$} \\
\hline Beams & $106(139)$ & $149(195)$ & $199(261)$ & $242(316)$ & $256(335)$ & $319(418)$ \\
\hline Columns & $102(133)$ & $131(171)$ & $162(212)$ & $179(234)$ & $196(256)$ & $230(301)$ \\
\hline Volume & $208(272)$ & $280(366)$ & $362(473)$ & $421(550)$ & $452(591)$ & $550(719)$ \\
\hline \multicolumn{7}{c}{ Volume of concrete per unit area of building, $\mathrm{m}^{3} / \mathrm{m}^{2}\left(\mathrm{ft}^{3} / \mathrm{ft}^{2}\right)$} \\
\hline Columns & $0.05(0.16)$ & $0.07(0.23)$ & $0.10(0.33)$ & $0.12(0.39)$ & $0.13(0.43)$ & $0.16(0.52)$ \\
\hline Total & $0.05(0.16)$ & $0.06(0.20)$ & $0.08(0.26)$ & $0.09(0.30)$ & $0.10(0.33)$ & $0.11(0.36)$ \\
\hline
\end{tabular}

$1.28 \mathrm{~m}^{2}$, the effective wall area $A_{\text {we }}$, determined using Eq. (13), is $2.2 \mathrm{~m}^{2}$, and the required concrete wall area $A_{w}$ is $0.8 \mathrm{~m}^{2}$. A first trial is calculated using the minimum wall thickness of $200 \mathrm{~mm}$. The value of $A_{w}$ for two $7.5 \mathrm{~m}$ walls (E-W direction) is $3.0 \mathrm{~m}^{2}$ and is $2.4 \mathrm{~m}^{2}$ for two $6.0 \mathrm{~m}$ walls (N-S direction). The same girder dimensions used for the case of the structure without walls (Case 2.0-nw) were employed: $600 \mathrm{~mm}$-deep x $300 \mathrm{~mm}$-wide girders were selected in both directions.

Drift check (Step 2)-The fundamental periods calculated using the Rayleigh method were $T_{E W}=0.32 \mathrm{~s}$ and $T_{N S}=0.38 \mathrm{~s}$. The effective initial period in each direction was obtained by multiplying the calculated values based on uncracked section properties by $\sqrt{2}$ to obtain 0.45 and $0.54 \mathrm{~s}$ for the $\mathrm{E}-\mathrm{W}$ and $\mathrm{N}-\mathrm{S}$ directions, respectively. The story drift ratios computed using Eq. (6) were 0.8 and $0.9 \%$ for the E-W and N-S directions, respectively. In this case, the calculated story drift ratios were approximately $1 / 2$ of the limiting value established as part of the performance objective $(\mathrm{SDR}=2 \%, \mathrm{MDR}=1.5 \%$ ). Because of the minimum column area required to carry gravity loads and the minimum wall thickness requirements, the structural index that results is more than twice than needed, which explains the conservative results.

Check for base shear strength (Step 3)-The possible collapse mechanisms were analyzed (Fig. 4). A minimum base shear strength of approximately $6150 \mathrm{kN}$, corresponding to $30 \%$ of the weight of the building, was obtained for direction N-S and approximately $6200 \mathrm{kN}$ for direction $\mathrm{E}-\mathrm{W}$, corresponding to $30 \%$ of the weight of the building. The calculated $T_{\text {eff }} / T_{S}$ were 0.81 and 0.96 for the E-W and N-S directions, respectively (the maximum allowable value of 0.83 is used). The value of the base shear strength obtained from the collapse mechanisms must be compared with the minimum obtained from Eq. (8). For the E-W and N-S directions, a base shear strength of $0.09 \mathrm{~W}$ was required, which was satisfied by the calculated base shear strengths of $0.30 \mathrm{~W}$ in both directions.

Seismic detailing (Step 4)-The provisions used in the previous example apply to the wall structure with added provisions for the walls. The walls in this example frame between two columns. Because the columns are detailed with confinement designated over the full length of the column, natural boundary elements are provided.

\section{Proportioning of five-story building for SDR below $1.5 \%$}

Additional examples were carried out for the five-story building with two additional performance objectives. The seismic demand for the site remained at $S_{D S}=1.25 \mathrm{~g}$ with stiff soil conditions, while the allowable story drift ratios $S D R$ were reduced to 1.5 and $1.0 \%$ of the story height. The minimum ratio of area of vertical elements to total building floor area (SI) was 0.23 and $0.34 \%$ to meet the performance criteria with SDR of 1.5 and $1.0 \%$, respectively. Consequently, if square columns are used, the minimum column dimensions based on 
Table 2-Calculated response for two- and five-story structure with walls

\begin{tabular}{c|c|c|c|c|c}
\hline \multicolumn{7}{c}{ Element dimensions, mm (in.) } \\
\hline Number of stories & 5 & 5 & 5 & 5 & 2 \\
\hline Column dimension & $400(15.7)$ & $400(15.7)$ & $400(15.7)$ & $450(17.7)$ & $300(11.8)$ \\
\hline Beam depth & $600(23.6)$ & $600(23.6)$ & $600(23.6)$ & $600(23.6)$ & $550(21.7)$ \\
\hline Beam width & $300(11.8)$ & $300(11.8)$ & $300(11.8)$ & $300(11.8)$ & $250(9.8)$ \\
\hline Wall thickness E-W & $150(5.9)$ & $200(7.9)$ & $250(9.8)$ & $350(13.8)$ & $150(5.9)$ \\
\hline Wall thickness N-S & $150(5.9)$ & $200(7.9)$ & $250(9.8)$ & $450(17.7)$ & $150(5.9)$ \\
\hline SI, E-W (N-S) & $0.38(0.29)$ & $0.48(0.37)$ & $0.58(0.45)$ & $0.81(0.77)$ & $0.99(0.79)$ \\
\hline \multicolumn{7}{|c|}{ Period verification, E-W, N-S } & \\
\hline Calculated period $T, \mathrm{~s}$ & $0.32,0.38$ & $0.30,0.36$ & $0.29,0.35$ & $0.26,0.30$ & $0.10,0.12$ \\
\hline Effective period $T_{e f f}, \mathrm{~s}$ & $0.45,0.54$ & $0.43,0.51$ & $0.40,0.49$ & $0.37,0.42$ & $0.14,0.17$ \\
\hline$S D R_{\text {est }} \%$ (Eq. (6)) & $0.76,0.91$ & $0.72,0.87$ & $0.68,0.83$ & $0.61,0.71$ & $0.59,0.71$ \\
\hline \multicolumn{7}{|c|}{ Strength verification, E-W, N-S } \\
\hline$V_{b} / W$ & $0.30,0.20$ & $0.32,0.31$ & $0.30,0.21$ & $0.32,0.23$ & $0.82,0.51$ \\
\hline$V_{r} / W($ Eq. $(8))$ & $0.09,0.08$ & $0.11,0.08$ & $0.13,0.08$ & $0.17,0.12$ & $0.37,0.34$ \\
\hline
\end{tabular}

Elastic drift for fundamental mode using $5 \%$ damping response spectrum, $\alpha=0.5 \mathrm{~g}, \mathrm{E}-\mathrm{W}, \mathrm{N}-\mathrm{S}$

\begin{tabular}{c|c|c|c|c|c}
\hline Elastic MDR, \% & $0.36,0.64$ & $0.45,0.58$ & $0.40,0.54$ & $0.30,0.40$ & $0.08,0.12$ \\
\hline Maximum interstory drift ratio, \% & $0.44,0.78$ & $0.54,0.72$ & $0.49,0.67$ & $0.36,0.50$ & $0.09,0.14$ \\
\hline Story with maximum drift demand & 4 & 4 & 4 & 4 & 2 \\
\hline
\end{tabular}

Mass (weight) of reinforcing steel per unit area of building, $\mathrm{kg} / \mathrm{m}^{3}\left(\mathrm{lb} / \mathrm{ft}^{3}\right)$

\begin{tabular}{c|c|c|c|c|c}
\hline Column reinforcement & $5(1.0)$ & $5(1.0)$ & $5(1.0)$ & $6(1.3)$ & $4(0.8)$ \\
\hline Beam reinforcement & $12(2.5)$ & $12(2.5)$ & $12(2.5)$ & $12(2.5)$ & $12(2.5)$ \\
\hline Wall reinforcement & $1(0.2)$ & $2(0.4)$ & $2(0.4)$ & $3(0.6)$ & $1(0.2)$ \\
\hline Total reinforcement & $18(3.8)$ & $19(4.0)$ & $19(4.0)$ & $21(4.4)$ & $17(3.6)$ \\
\hline \multicolumn{6}{c|}{ Volume of concrete (beams, columns, and walls), $\mathrm{m}^{3}\left(\mathrm{yd}^{3}\right)$} \\
\hline Beams & $142(185)$ & $142(185)$ & $142(185)$ & $141(184)$ & $43.2(56.5)$ \\
\hline Columns & $38(49.6)$ & $38(49.6)$ & $38(49.6)$ & $48(62.8)$ & $9.9(11.6)$ \\
\hline Walls & $72(94.3)$ & $96(126)$ & $120(157)$ & $190(248)$ & $29.6(38.7)$ \\
\hline Volume & $252(329)$ & $276(360)$ & $300(392)$ & $379(495)$ & $81.7(107)$ \\
\hline
\end{tabular}

Volume of concrete per unit area of building, $\mathrm{m}^{3} / \mathrm{m}^{2}\left(\mathrm{ft}^{3} / \mathrm{ft}^{2}\right)$

\begin{tabular}{c|l|l|l|l|l}
\hline Beams & $0.07(0.23)$ & $0.07(0.23)$ & $0.07(0.23)$ & $0.07(0.23)$ & $0.05(0.16)$ \\
\hline Columns & $0.02(0.07)$ & $0.02(0.07)$ & $0.02(0.07)$ & $0.02(0.07)$ & $0.01(0.03)$ \\
\hline Walls & $0.06(0.20)$ & $0.04(0.13)$ & $0.05(0.16)$ & $0.09(0.30)$ & $0.04(0.13)$ \\
\hline Total & $0.15(0.49)$ & $0.12(0.39)$ & $0.14(0.46)$ & $0.19(0.62)$ & $0.10(0.33)$ \\
\hline
\end{tabular}

Eq. (13) are 750 and $950 \mathrm{~mm}$. Using these column dimensions as a reference and following the suggested guidelines for girder dimensions, several structures were proportioned and detailed for gravity and lateral loads. After each structure was proportioned, the period was calculated using gross section properties and the story drift ratio was estimated with Eq. (6). The base shear strength also was calculated based on the reinforcement required by Chapter 21 of the ACI 318-02 Building Code (ACI Committee 318 2002). The drifts listed in Table 1 were obtained using the flat-rate procedure. Elastic drift demands for model code design ground motion with $S_{D S}=1.25 \mathrm{~g}$ are presented in Table 1 as a comparative reference. Several alternatives were proportioned for the five-story structure without walls, and selected quantities are presented in Table 1. Structures with column dimensions of 750 and $950 \mathrm{~mm}$ yielded estimated story drift ratios (calculated with Eq. (6)) that were within the limiting values allowed by the performance criteria.

Preliminary dimensions for the two additional performance objectives were also estimated for the five-story building with structural walls. In these cases, column sizes were selected as the minimum necessary to sustain gravity loads, and the required wall thicknesses were determined based on a building layout with two walls in each direction (Fig. 3), each occupying the length of one bay. As previously indicated, the minimum ratios of effective vertical element to floor area (SI) were 0.23 and $0.34 \%$ for performance criteria with SDR of 1.5 and $1.0 \%$. Four trial structures with SI ranging from 0.24 to $0.61 \%$ were proportioned, and the results are presented in Table 2 . In the E-W direction, a building configuration with the minimum column size for gravity loads $(400 \mathrm{~mm})$ and minimum wall thickness $(200 \mathrm{~mm})$ results in a structural index of 0.48 , which is sufficient to meet the most stringent requirement (1.0\% SDR). In the N-S direction, the trial structure with the minimum wall thickness $(200 \mathrm{~mm})$ has a structural index of $0.37 \%$, which is also sufficient to meet the performance criterion of $1.0 \%$ SDR. In all cases, the estimates of drift based on Eq. (6) were within the limits specified by the performance objectives.

\section{DESIGN OF TWO-STORY EXAMPLE BUILDING}

Trial designs were completed for a two-story structure with similar floor configuration and performance objective as the five-story building (Fig. 3), with the goal of illustrating the use of the method under significantly different circumstances. The minimum column dimension for a configuration without walls calculated with Eq. (13) (for $S_{D S}$ 
Table 3-Calculated response for two-story structure without walls

\begin{tabular}{c|c|c|c}
\hline \multicolumn{5}{c}{ Element dimension, mm (in.) } \\
\hline Column dimension & $650(25.6)$ & $750(29.5)$ & $850(33.4)$ \\
\hline Beam depth & $550(21.7)$ & $650(25.6)$ & $750(29.5)$ \\
\hline Beam width & $300(11.8)$ & $350(13.8)$ & $350(13.8)$ \\
\hline SI & 0.42 & 0.56 & 0.71 \\
\hline Period verification, E-W, N-S \\
\hline Calculated period $T, \mathrm{~s}$ & $0.31,0.28$ & $0.23,0.21$ & $0.19,0.17$ \\
\hline Effective period $T_{\text {eff }}, \mathrm{s}$ & $0.43,0.40$ & $0.33,0.30$ & $0.26,0.24$ \\
\hline$S D R_{\text {est }}, \%$ (Eq. (6)) & $1.81,1.67$ & $1.36,1.25$ & $1.09,1.00$ \\
\hline Correction factor & $0.90,0.91$ & $0.78,0.78$ & $0.64,0.64$ \\
\hline \multicolumn{5}{c}{$S D R_{\text {est }}, \%$} & $1.63,1.52$ & $1.06,0.98$ & $0.70,0.64$ \\
\hline \multicolumn{4}{c}{ Strength verification, E-W, N-S } \\
\hline$V_{b} / W$ & $0.61,0.42$ & $0.70,0.61$ & $0.88,0.82$ \\
\hline$V_{r} / W($ Eq. (8)) & $0.11,0.14$ & $0.21,0.23$ & $0.27,0.29$ \\
\hline \multicolumn{4}{c}{ Strength requirement is met for all cases } \\
\hline
\end{tabular}

Elastic drift for fundamental mode using a 5\% damping response spectrum with $\alpha=0.5 g$, E-W, N-S

\begin{tabular}{c|c|c|c}
\hline Elastic MDR, \% & $0.55,0.47$ & $0.31,0.26$ & $0.20,0.17$ \\
\hline $\begin{array}{c}\text { Maximum interstory } \\
\text { drift ratio, \% }\end{array}$ & $0.63,0.52$ & $0.35,0.29$ & $0.23,0.18$ \\
\hline $\begin{array}{c}\text { Story with maximum } \\
\text { drift demand }\end{array}$ & 2 & 2 & 2 \\
\hline
\end{tabular}

Mass (weight) of reinforcing steel per unit area of building, $\mathrm{kg} / \mathrm{m}^{2}\left(\mathrm{lb} / \mathrm{ft}^{2}\right)$

\begin{tabular}{c|l|l|l}
\hline Column reinforcement & $12(2.5)$ & $13(2.7)$ & $14(2.9)$ \\
\hline Beam reinforcement beams & $10(2.0)$ & $14(2.9)$ & $19(3.9)$ \\
\hline Total reinforcement & $22(4.5)$ & $27(5.6)$ & $33(6.8)$ \\
\hline
\end{tabular}

Volume of concrete (beams and columns), $\mathrm{m}^{3}\left(\mathrm{yd}^{3}\right)$

\begin{tabular}{l|c|c|c} 
Beams & $50.9(66.5)$ & $69.6(91.0)$ & $79.7(104.2)$ \\
\hline Columns & $41.9(54.8)$ & $54.0(70.6)$ & $67.1(87.6)$ \\
\hline Volume & $92.8(121.3)$ & $123.6(161.5)$ & $146.8(191.8)$ \\
\hline
\end{tabular}

Volume of concrete per unit area of building, $\mathrm{m}^{3} / \mathrm{m}^{2}\left(\mathrm{ft}^{3} / \mathrm{ft}^{2}\right)$

\begin{tabular}{c|l|l|l} 
Beams & $0.06(0.21)$ & $0.09(0.29)$ & $0.10(0.33)$ \\
\hline Columns & $0.05(0.17)$ & $0.07(0.23)$ & $0.08(0.28)$ \\
\hline Total & $0.11(0.52)$ & $0.15(0.52)$ & $0.18(0.61)$ \\
\hline
\end{tabular}

$=1.25 \mathrm{~g}$ and SDR of $2.0 \%$ ) was approximately $650 \mathrm{~mm}$, which corresponds to an SI of $0.42 \%$. Several different trial designs for the two-story structure were completed with SI ranging from 0.42 to $0.71 \%$. Selected results, summarized in Table 3, indicate that the structure with the $650 \mathrm{~mm}$ columns met the performance objective of $2.0 \%$ story drift ratio and the drift values calculated with Eq. (6) were within the limits established by the performance objective. For performance objectives below $2.0 \%$ SDR, column sizes proportioned to sustain gravity loads resulted in very flexible structures and did not have sufficient lateral stiffness to meet the stated performance criteria. In this case, the governing design consideration was stiffness rather than strength.

As column dimensions were increased to meet the performance criterion, the combination of larger column sizes and minimum reinforcement requirements implied a considerable increase in base shear strength. As previously stated, for structures with effective periods below the characteristic period of the ground motion, Eq. (6) was shown to provide an adequate estimate of the drift demand in cases where the ratio of base shear strength to elastic shear demand was low (Lepage 1997). For buildings with base shear strength higher than approximately $30 \%$ of the weight and with an effective
Table 4-Preliminary column and wall dimensions for two- and five-story structures with walls

\begin{tabular}{c|c|c|c|c}
\hline Roof height, $\mathrm{mm}(\mathrm{ft})$ & $17.8(58.4)$ & $17.8(58.4)$ & $17.8(58.4)$ & $7.3(23.9)$ \\
\hline$S D R_{\text {all }}, \%$ & 2.00 & 1.50 & 1.00 & 2.00 \\
\hline$C_{p}{ }^{*}$ & 0.17 & 0.23 & 0.34 & 0.42 \\
\hline Number of stories & 5 & 5 & 5 & 2 \\
\hline Total floor area, $\mathrm{m}^{2}\left(\mathrm{ft}^{2}\right)$ & $\begin{array}{c}2030 \\
(21,800)\end{array}$ & $\begin{array}{c}2030 \\
(21,800)\end{array}$ & $\begin{array}{c}2030 \\
(21,800)\end{array}$ & $\begin{array}{c}810 \\
(8720)\end{array}$ \\
\hline Column depth, $\mathrm{mm}(\mathrm{ft})$ & $400(15.7)$ & $400(15.7)$ & $400(15.7)$ & $300(11.8)$ \\
\hline$\Sigma A_{c e}{ }^{\dagger}, \mathrm{m}^{2}\left(\mathrm{ft}^{2}\right)$ & $1.28(13.8)$ & $1.28(13.8)$ & $1.28(13.8)$ & $0.72(7.8)$ \\
\hline$A_{w e}$ required $^{\ddagger}, \mathrm{m}^{2}\left(\mathrm{ft}^{2}\right)$ & $2.21(23.8)$ & $3.37(36.3)$ & $5.70(6.13)$ & $2.68(28.8)$ \\
\hline$A_{w} \mathrm{E}-\mathrm{W}^{\S}, \mathrm{m}^{2}\left(\mathrm{ft}^{2}\right)$ & $0.80(8.6)$ & $1.21(13.1)$ & $2.05(22.1)$ & $0.83(8.9)$ \\
\hline $\begin{array}{c}\text { Required wall } \\
\text { thickness E-W, mm (in.) }\end{array}$ & $53(2.1)$ & $81(3.2)$ & $137(5.4)$ & $60(2.3)$ \\
\hline$A_{w} \mathrm{~N}-\mathrm{S}^{\S}, \mathrm{m}^{2}\left(\mathrm{ft}^{2}\right)$ & $0.86(9.3)$ & $1.31(14.1)$ & $2.22(23.9)$ & $0.83(8.9)$ \\
\hline $\begin{array}{c}\text { Required wall } \\
\text { thickness N-S, mm (in.) }\end{array}$ & $72(2.8)$ & $110(4.3)$ & $185(7.3)$ & $74(2.9)$ \\
\hline
\end{tabular}

${ }^{*}$ For performance objective with $S_{D S}=1.25, T_{S}=0.55$.

† Sixteen columns per floor.

${ }^{\ddagger}$ Area per floor $=405 \mathrm{~m}^{2}\left(4360 \mathrm{ft}^{2}\right)$.

${ }^{\S} \mathrm{E}-\mathrm{W}$ has two walls with $L_{w}=7.5 \mathrm{~m}(24.6 \mathrm{ft})$ and N-S has two walls with $L_{w}=6.0 \mathrm{~m}$ (19.7 ft).

period below the characteristic period of the design ground motion, the drift demand estimated using Eq. (6) may be overly conservative. In these cases, the correction factor given by Eq. (9) was applied to the story drift ratios calculated with Eq. (6).

The two-story building with walls was proportioned based on the minimum column dimensions required to sustain gravity loads ( $300 \mathrm{~mm}$ in this particular case), selecting the minimum wall thickness to meet the performance objective as indicated by Eq. (13). The required wall thickness for a story drift ratio of $2.0 \%$ was $60 \mathrm{~mm}$ (Table 4), which was less than the recommended $200 \mathrm{~mm}$ minimum wall thickness. The trial design was completed with a wall thickness of $150 \mathrm{~mm}$, which resulted in an SI of $0.79 \%$ and an effective period of $0.17 \mathrm{~s}$ in the $\mathrm{N}-\mathrm{S}$ direction (Table 2). Because minimum dimensions controlled the design, the configuration that was selected had an SI $(0.79 \%)$ significantly higher than the value suggested by Eq. (10) and (12) $(\mathrm{SI}=0.42 \%)$ and resulted in an estimated SDR of $0.7 \%$, considerably less than the allowable. A comparison of the trial designs for the two-story building clearly shows that a configuration with structural walls was significantly more effective in achieving the stated performance objective than one with structural frames.

\section{ECONOMICAL CONSIDERATIONS OF USING STRUCTURAL WALLS VERSUS MOMENT RESISTING FRAMES}

Results for the two- and five-story buildings showed that configurations with structural walls were more effective than those with moment resisting frames in achieving the stated performance objectives. A comparison in terms of the cost of the two configurations was carried out based on two parameters: the volume of concrete (Fig. 5) and the weight of reinforcing steel (Fig. 6) per unit area of building. These two quantities were calculated for each trial structure and summarized in Table 1 to 3 . Additional structures were proportioned to provide a better representation of the trends in the data.

Figure 5 and 6 indicate that for building configurations with structural walls, regardless of the number of stories, the mean drift ratio did not decrease significantly when the volume of 


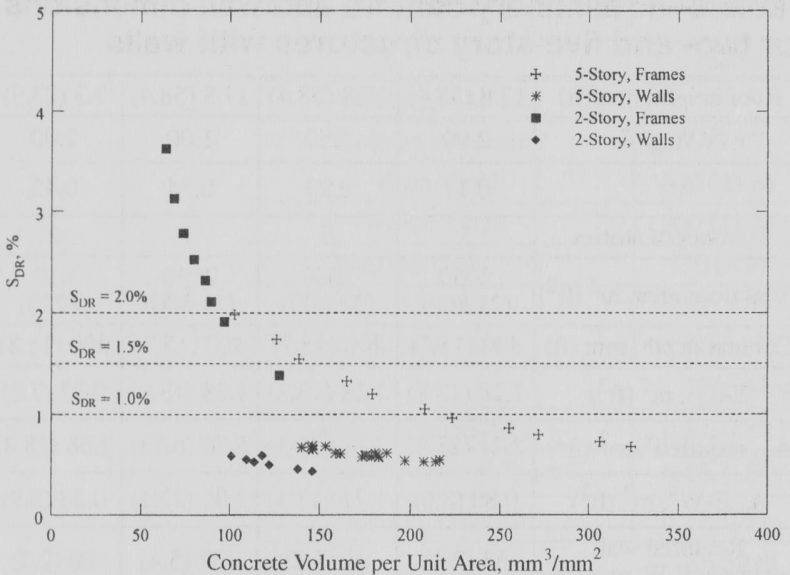

Fig. 5-Estimated story drift ratio versus volume of concrete per unit area for various configurations of example building.

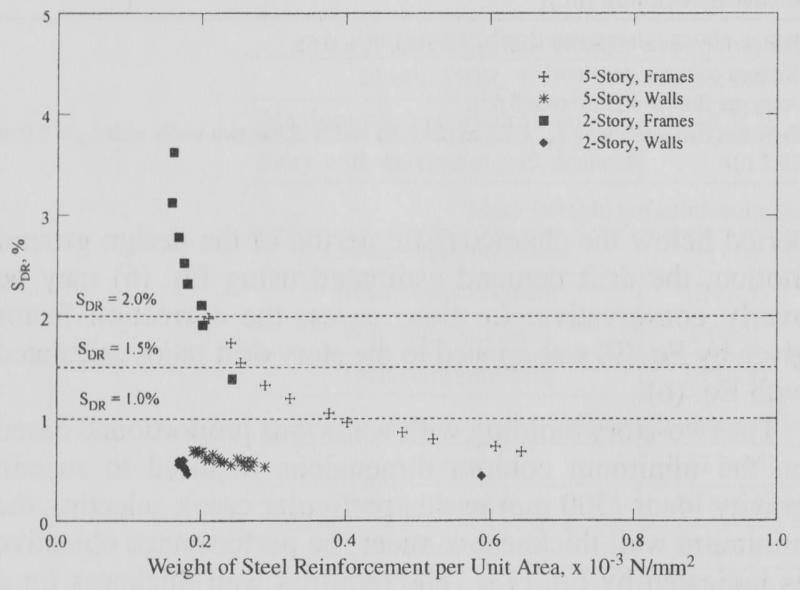

Fig. 6-Estimated story drift ratio versus weight of reinforcement per unit area for various configurations of example building.

concrete and weight of steel per unit building area increased. Given the length of the walls in the building configurations that were studied, the use of the minimum wall thickness resulted in low values of SDR and there was little benefit gained by increasing their thickness and thus the volume of concrete and weight of steel per unit area. Conversely, in configurations with moment resisting frames, the effect of increasing column and girder sizes had a significant effect on the estimated mean drift ratio. Comparing the performance of both structural systems, it is evident that configurations with the minimum wall thickness were significantly more costeffective in achieving the stated performance objectives than those with moment resisting frames and similar volumes of concrete and steel per unit area of building.

\section{SUMMARY AND CONCLUSIONS}

A method was presented for proportioning low- and medium-rise reinforced concrete building structures that are regular in plan and elevation. The method is intended to evaluate in a simple manner the expected level of performance of building structures for a particular earthquake demand. The main advantages offered by the flat-rate method are that it is simple and that it requires a minimum number of assumptions and calculations to assess the adequacy of a proposed structural configuration to achieve a stated performance objective. The method is best used for preliminary design/analysis when

seismic analysis experience is limited (for example, regions of moderate seismicity or underdeveloped countries) or for evaluating the seismic vulnerability of a large number of structures for possible retrofit.

The method comprises four basic steps that are described in detail: 1) define preliminary dimensions of the structural elements; 2) verify compliance with an allowable drift limit; 3 ) verify if the minimum strength requirements are met; and 4) detail the structural elements for toughness. To illustrate the use of the method, a number of trial designs were completed using two structural configurations for buildings with two and five stories and three different performance objectives. The lateral load resisting system for the first structural configuration consisted of moment resisting frames only, and the second configuration had a combination of walls and frames in which the structural walls were the primary lateral load resisting elements.

The trial designs showed that for buildings located in zones of high seismic risk and proportioned with moment resisting frames and structural walls, element dimensions determined with Eq. (10) to (13) were capable of achieving the performance criterion given by Eq. (10). In the case of low-rise structures (two stories) with moment resisting frames, it was found that to meet the performance criteria given by Eq. (14), the governing consideration was stiffness rather than strength and final column dimensions were considerably higher than the minimum necessary to sustain gravity loads. A comparison of all trial designs in terms of the average volume of concrete and weight of steel per unit area of building showed that structural walls were more costeffective than moment resisting frames in order to meet any of the three stated performance objectives.

\section{NOTATION}

$A_{c}$

$A_{f t}$

$A_{w}$

$A_{\text {we }}$

$C_{p}$

$C_{\alpha}=$ acceleration amplification factor

$C F_{M D R}=$ correction factor for estimated mean drift ratio

$D_{\text {roof }}=$ roof displacement

$g=$ acceleration of gravity

$H \quad=$ total column height (between girder centers)

$H_{\text {wall }}=$ total height of structural wall

$h=$ largest column dimension

$h_{g} \quad=\quad$ total girder depth

$h_{\text {roof }}=$ height of structure

$L=$ girder span length (between column centers)

$L_{\text {wall }}=$ total wall length

MDR = mean drift ratio; ratio of total lateral drift at roof to total building height

$M D R_{\text {all }}=$ allowable mean drift ratio

$M D R_{\text {est }}=$ estimated mean drift ratio

$N_{\text {stories }}=$ number of stories

$N_{T S}=10 T_{S}$

$S_{D 1} \quad=$ design spectral response acceleration parameter for period of $1 \mathrm{~s}$, expressed as fraction of $g$

$S_{D S} \quad=$ design short-period spectral response acceleration parameter, expressed as fraction of $g$

SDR = story drift ratio; ratio of story drift to story height

$S D R_{\text {est }}=$ estimated story drift ratio

$S D R_{\text {all }}=$ acceptable story drift ratio

$S_{d} \quad=$ spectral displacement

SI $=$ structural index

$T_{S} \quad=\quad$ characteristic period for site (longest period defining nearly

constant spectral acceleration region) $\left(S_{D 1} / S_{D S}\right)$

$T_{\text {eff }} \quad=\quad$ effective initial period for building

$T_{i} \quad=$ fundamental period of vibration for building calculated 
using gross section properties

smallest column dimension

wall thickness

base shear strength of the structure

minimum required base shear strength

weight of building

effective peak ground acceleration as fraction of acceleration of gravity

modal participation factor

\section{REFERENCES}

ACI Committee 318, 2002, "Building Code Requirements for Structural Concrete (ACI 318-02) and Commentary (318R-02)," American Concrete Institute, Farmington Hills, Mich., 443 pp.

Browning, J., 2001, "Proportioning of Earthquake-Resistant RC Building Structures," Journal of Structural Engineering, ASCE, V. 127, No. 2, pp. 145-151.

FEMA 368, 2001, "NEHRP Recommended Provisions for Seismic Regulations for New Buildings," Building Seismic Safety Council, Washington, D.C., 374 pp.

Frankel, A. D.; Mueller, C. S.; Barnhard, T. P.; Leyendecker, E. V.; Wesson, R. L.; Harmsen, S. C.; Klein, F. W.; Perkins, D. M.; Dickman, N. C.; Hanson, S. L.; and Hopper, M. G., 2000, "USGS National Seismic Hazard Maps," Earthquake Spectra, V. 16, No. 1, pp. 1-19.

García, L. E., 1996, "Economic Considerations of Displacement-Based Seismic Design of Structural Concrete Buildings," Structural Engineering International, IABSE, V. 6, No. 4, Zurich, Switzerland.

IBC, 2003, "International Building Code 2003," published in cooperation by BOCA, ICBO, and SBCCI, International Code Council, Falls Church, Va., $632 \mathrm{pp}$.

Hasaan, A., and Sozen, M., 1997, "Seismic Vulnerability Assessment of Low-Rise Buildings in Regions with Infrequent Earthquakes," ACI Structural Journal, V. 94, No. 1, Jan.-Feb., pp. 31-39.

Lepage, A., 1997, "A Method for Drift-Control in Earthquake-Resistant Design of Reinforced Concrete Building Structures," PhD thesis, University of Illinois at Urbana-Champaign, Urbana, Ill.

Matamoros, A.; Browning, J.; and Luft, M., 2003, "Evaluation of Simple Methods for Estimating Drift of Reinforced Concrete Buildings Subjected to Earthquakes," Earthquake Spectra, V. 19, No. 4, Nov., pp. 839-861.

Moehle, J., 1984, "Strong Motion Drift Estimates for R/C Structures," Journal of the Structural Division, ASCE, V. 110, No. ST9, Sept., pp. 1988-2001.

Newmark, N. M., and Hall, W. J., 1982, "Earthquake Spectra and Design," EERI Monograph Series, 103 pp.

NFPA, 2003, "NFPA 5000-NFPA Building Construction and Safety Code," National Fire Protection Association, Quincy, Mass., 505 pp.

Otani, S., and Sozen, M. A., 1972, "Behavior of Multi-Story Reinforced Concrete Frames During Earthquakes," Structural Research Series No. 392, Civil Engineering Studies, University of Illinois at Urbana-Champaign, Urbana, Ill.

Ozturk, B., 2003, "Seismic Drift Response of Building Structures in Seismically Active and Near-Fault Regions," $\mathrm{PhD}$ thesis, Purdue University, West Lafayette, Ind.

SEI/ASCE, 2003, "Minimum Design Loads for Buildings and Other Structures (SEI/ASCE 7-02)," Structural Engineering Institute, ASCE, Reston, Va., $376 \mathrm{pp}$

Shibata, A., and Sozen, M., 1976, "Substitute-Structure Method for Seismic Design in Reinforced Concrete," Journal of the Structural Division, ASCE, V. 102, No. ST3, pp. 1-18.

Shimazaki, K., and Sozen, M., 1984, "Seismic Drift of Reinforced Concrete Structures," Technical Research Report of Hazama-Gumi Ltd., pp. 145-166

Sozen, M. A., 1981, "Review of Earthquake Response of R/C Buildings with a View of Drift Control," State-of-the-Art in Earthquake Engineering1981, O. Ergunay and M. Erdik, ed., Ankara, Turkey, Oct., pp. 383-418.

Uniform Building Code (UBC), 1997, "Structural Engineering Design Provisions," V. 2, Whittier, Calif

\section{APPENDIX \\ Development of design equations}

Indexes SI and $\mathrm{C}_{\mathrm{p}}$ - The premise of the flat-rate method is to provide enough lateral stiffness in a structure with the intention of controlling the displacement response to within an acceptable level. The use of this method is limited to regular and low-rise structures, in which roof drift can be estimated using a single-degree-of-freedom oscillator, and the contribution of higher modes does not significantly affect the distribution of drift over the height of the structure. Because drift is adopted as an indicator of performance, and drift is primarily dependent on the effective initial period (Shimazaki and Sozen 1984), performance is related to the ratio of mass to stiffness in the structure. The flat-rate method implements simple equations that reflect the relationship between the ratio of mass to stiffness of a structure and the expected drift demand. An equation developed by Hasaan and Sozen (1997) considering a wealth of structural damage information gathered after the Erzincan earthquake of 1992 was adopted as a simple measure of the ratio of lateral stiffness to mass of a structure. The equation was later modified to account for the effect of the height-to-length ratio of walls (Matamoros, Browning, and Luft 2003). The SI is defined as

$$
\mathrm{SI}=100 \cdot \frac{A_{c e}+A_{w e}}{A_{f t}}, A_{w e}=\frac{100 A_{w t}}{30+\left(H_{\text {wall }} / L_{\text {wall }}\right)^{2}}
$$

where

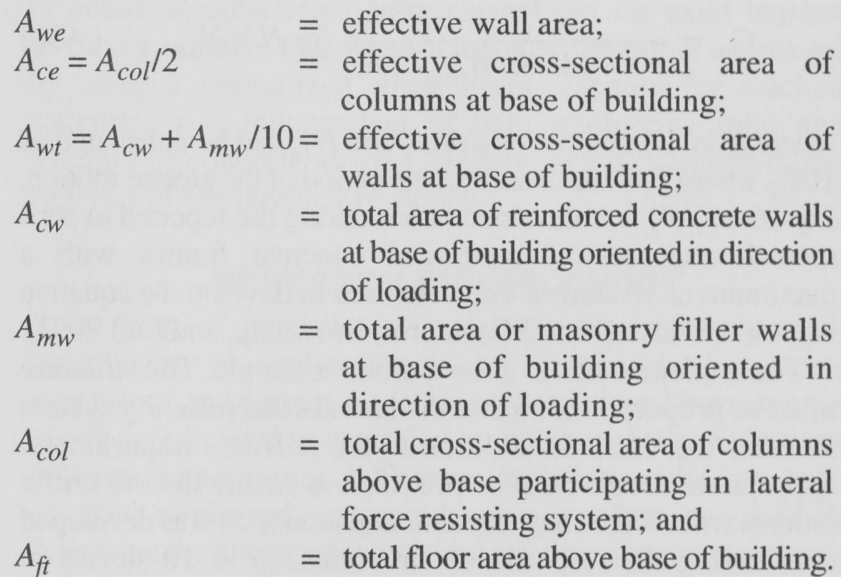

To assess the vulnerability of a structure subjected to a given earthquake demand, acceptable limits for SI consistent with the performance objective for the structure must be established. Those limits are defined by introducing a performance constant $C_{p}$ such that

$$
C_{p} \leq \mathrm{SI}
$$

Based on damage surveys obtained from buildings after the 1992 Erzincan earthquake in Turkey (peak ground acceleration of approximately $0.5 \mathrm{~g}$ ), Hasaan and Sozen suggested values for $C_{p}$ of 0.25 and 0.50 for performance levels of life safety and immediate occupancy. The study by Hasaan and Sozen was based on structures ranging from one to five stories, most of which did not have proper detailing.

Matamoros, Browning, and Luft (2003) conducted studies using additional data from shaking table experiments. They proposed the following relationship between the performance constant and the mean drift ratio, for a peak ground acceleration of $0.5 \mathrm{~g}$

$$
C_{p}=\frac{50}{\mathrm{MDR} \cdot h_{\text {roof }}}
$$

where $\mathrm{MDR}=$ target mean drift ratio, ratio of maximum roof drift to total building height; and $h_{\text {roof }}=$ building height, $\mathrm{mm}$.

Equation (A3) yields MDR values of $200 / h_{\text {roof }}(\mathrm{mm})$ and $100 / h_{\text {roof }}(\mathrm{mm})$ for values of $C_{p}$ of 0.25 and 0.50 . For a threestory structure with $h_{\text {roof }}=10,000 \mathrm{~mm}$, the MDR values that 
correspond to the performance limits specified by Hasaan and Sozen are 2 and 1\%. As indicated in Matamoros, Browning, and Luft (2003), Eq. (A3) can be adjusted to account for different levels of demand.

$$
C_{p}=\frac{\alpha \cdot g}{100 \cdot \mathrm{MDR} \cdot h_{\text {roof }}}
$$

where $\alpha$ = effective peak ground acceleration (normalized to the acceleration of gravity). Equation (A4) can be used to establish evaluation criteria for different levels of performance and demand.

\section{Performance evaluation for midrise structures}

Equation (A4) was adjusted to account for the reduction in the design spectrum that occurs for medium rise buildings

$$
\begin{gathered}
C_{p}=\frac{\alpha \cdot g}{100 \cdot \mathrm{MDR} \cdot h_{\text {roof }}} \text { for } N \leq N_{T s} \\
C_{p}=\frac{\alpha \cdot g}{100 \cdot \mathrm{MDR} \cdot h_{\text {roof }}} \cdot \frac{N_{T s}}{N} \text { for } N \geq N_{T s}
\end{gathered}
$$

where $N$ is the number of stories and $N_{T S}$ can be calculated as $10 T_{S}$, where $T_{S}$ is the characteristic period of the ground motion. Equation (A5) was developed considering the reported experimental responses of reinforced concrete frames with a maximum of 10 stories. The data used to develop the equation is presented elsewhere (Matamoros, Browning, and Luft 2003).

The implementation of the method is simple. The structure must be proportioned so that the lateral-load resisting system satisfies Eq. (A2). In addition to the stiffness requirement, appropriate details must be provided to ensure that no brittle failures will occur in any element. Equation (A5) was developed considering the response of structures up to 10 stories in height, and the correlation between the performance constant $C_{p}$ and the mean drift ratio as indicated by Eq. (A5) degrades as the number of stories increases.

\section{Equation for $M D R_{\text {est }}$}

The estimated mean drift ratio given by Eq. (A5) is based on a representative displacement design spectrum proposed by Lepage (1997). The simplified spectrum is defined by assuming a linear relationship between spectral displacement $S_{d}$ and period $T$

$$
S_{d}=\frac{C_{\alpha} \cdot \alpha \cdot g \cdot T_{S}}{(2 \pi)^{2}} \cdot T_{e f f}
$$

where $C_{\alpha}$ is the acceleration amplification factor; $\alpha$ is the effective peak ground acceleration expressed as a coefficient of the acceleration of gravity; $g$ is the acceleration of gravity; $T_{S}$ is the characteristic period of the ground motion; and $T_{\text {eff }}$ is the effective initial period of the structure. Research by Shimazaki and Sozen (1984) and Lepage (1997) showed that if $T_{e f f}$ is calculated using $\sqrt{2} \cdot T_{i}$, where $T_{i}$ is the fundamental period of the structure based on gross section properties, then a linear displacement spectrum using $C_{\alpha}=3.7$ provided a reasonable bound for the nonlinear displacements. For a multistory building, the spectral displacement $S_{d}$ is related to the roof displacement by means of Eq. (A7)

$$
D_{\text {roof }}=\gamma \cdot S_{d}
$$

where $\gamma$ corresponds to the modal participation factor calculated using a shape vector $\phi_{i}$ normalized to unity at the roof and is representative of the predominant deflected shape of the building. A value for the $\gamma$ factor of 1.3 is assumed representative for the fundamental mode of low-rise regular structures. The estimated mean drift ratio $M D R_{\text {est }}$, in terms of the effective initial period, is obtained using Eq. (A6) combined with Eq. (A7). For $\gamma=1.3$, an expression for MDR is given by

$$
M D R_{\text {est }}=\frac{C_{\alpha} \cdot \alpha \cdot g \cdot T_{S} \cdot T_{\text {eff }}}{30 \cdot h_{\text {roof }}}
$$

\section{Correction factor for $M D R_{\text {est }}$}

For structures with an effective period smaller than the characteristic period of the ground motion $\left(T_{\text {eff }}<T_{g}\right)$, the relationship between spectral displacement and period is given by

$$
S_{d}=\frac{C_{\alpha} \cdot \alpha \cdot g}{(2 \pi)^{2}} \cdot T_{e f f}^{2}
$$

For the same range of periods, Lepage (1997) proposed the following relationship for the ratio of nonlinear to linear displacement response

$$
D R=\frac{\left(1-V_{b} / V_{\text {elast }}\right) \cdot T_{S}}{T_{\text {eff }}}+\frac{V_{b}}{V_{\text {elast }}}
$$

where

$D R=$ nonlinear to linear displacement ratio;

$V_{b} \quad=$ calculated base shear strength; and

$V_{\text {elast }}=$ elastic shear demand that corresponds to design acceleration response spectrum.

If the quantity $V_{b} / V_{\text {elast }}$ is small, Eq. (A10) has an upper bound given by

$$
D R=\frac{T_{S}}{T_{e f f}}
$$

For buildings with $T_{\text {eff }}<T_{S}$, Eq. (A6) was obtained as the product of the spectral displacement given by Eq. (A9) and the factor $D R$ defined in Eq. (A11). If $V_{b} / V_{\text {elast }}$ is not negligible, however, the ratio of linear to nonlinear displacement is affected by the base shear strength. In this case, an improved estimate of the displacement can be obtained by multiplying the results from Eq. (A6) and (A8) by a correction factor, which is given by the ratio of Eq. (A10) to Eq. (A11)

$$
C F_{M D R}=1-\frac{V_{b}}{V_{\text {elast }}}+\frac{T_{\text {eff }}}{T_{S}} \cdot \frac{V_{b}}{V_{\text {elast }}} \leq 1.0
$$

In the short period range, the elastic shear demand $V_{\text {elast }}$ is defined as the product of $\mathrm{C}_{\alpha} \cdot \alpha \cdot W$. Thus, Eq. (A12) may be rewritten as

$$
C F_{M D R}=1-\frac{V_{b} / W}{C_{\alpha} \cdot \alpha}\left(1-\frac{T_{e f f}}{T_{S}}\right) \leq 1.0
$$

where $W$ is the weight of the building. 